\title{
CAMPO E CIDADE: GRANDE SERTÃO E TRISTES TRÓPICOS
}

\author{
Abel S. Viana \\ Doutorando em Literatura - UFSC
}

Resumo: Até que ponto o aprimoramento intelectual possibilitou melhoria nas relações sociais entre campo e cidade no Brasil de meados do século XX? As imagens articuladas e expostas por importantes intelectuais estavam muitas vezes vinculadas a uma suposta necessidade de políticas públicas dirigidas ao habitante do campo. A constatação leva a pelo menos duas questões: o mascaramento de uma construção humana - o Estado democrático - pautada em uma pseudo-unidade política, social e cultural, quando não racial; e, por conseqüência, a subjugação de grupos sociais marginalizados, dos quais o habitante do campo é um exemplo. Para a avaliação deste problema, há dois textos fundamentais, por unirem uma dimensão importante para se pensar a representação e homogeneização estatal: serem centrais no debate sobre a relação campo-cidade, mantendo diálogo com o pensamento acadêmico de sua época. Estas obras, das quais trata o artigo, são Tristes trópicos, de Lévi-Strauss, e Grande sertão: veredas, de Guimarães Rosa.

Palavras-chave: Representação; Estado; Campo; Guimarães Rosa; Claude Lévi-Strauss.

\begin{abstract}
Until what point the intellectual improvement made possible the improvement in the social relations between field and city in Brazil of 20th century middle? The articulated and displayed images by important intellectuals were many times entailed to a supposed necessity of governmental public politics directed to the field inhabitant. The constatation takes us to at least two questions: the disguise of a superficial human being construction, which is, the idea of democratic State, based in a false politics unit, social and cultural, when not racial; and, as a consequence, the subjugation of social groups kept out of society, which the field inhabitant is one example. For the evaluation of this problem, we have two basic texts, for joining a important dimension to think about the problem of the representation and state homogenization: for being central in the debate on the relation field-city, and to establish dialogue with the academic thought of its time. These workmanships, which the article talks about, are Tristes trópicos, by Claude Lévi-Strauss, and Grande sertão: veredas by João Guimarães Rosa.
\end{abstract}

Keywords: Representation; State; Field; Guimarães Rosa; Claude Lévi-Strauss. 
O sábio não é o homem que fornece as verdadeiras respostas; é o que formula as verdadeiras perguntas.

Claude Lévi-Strauss

Mestre não é quem sempre ensina, mas quem de repente aprende. João Guimarães Rosa

À primeira vista, poderíamos pensar que as frases acima encerram a mesma idéia. Em ambas é central que a consciência da incerteza é mais válida que a crença na verdade. Todavia, não podemos desprezar o lugar de onde se pronunciam estas máximas, e isso indica algumas diferenças profundas. O antropólogo francês individualiza o questionamento; ao passo que o escritor brasileiro pressupõe o diálogo pois aprender, diferentemente do questionamento científico, é aprender com o outro.

Publicado na França em 1955, Tristes trópicos é considerado marco da antropologia contemporânea. Autobiográfico, etnográfico e itinerante, o livro baseia-se na estada de Lévi-Strauss no Brasil entre 1935 e 1938, tempo durante o qual lecionou na Universidade de São Paulo. Neste contexto acadêmico, Lévi-Strauss organiza sua primeira expedição etnográfica, às tribos dos índios cadiuéus e bororos, no Mato Grosso. Este livro e sua presença no Brasil são muito importantes para sua obra. Edmund Leach, um de seus comentadores, chega a afirmar que todas as teorias de LéviStrauss amparam-se na experiência descrita em Tristes trópicos (LEACH, 1995).

Porém, não são apenas seus méritos antropológicos que tornam o livro interessante para o debate entre o campo e a cidade no Brasil. O que prontamente causa interesse é que Lévi-Strauss, ao dedicar o primeiro capítulo à cidade de São Paulo, opõe-se a um discurso estatal de modernização no qual se ampara negativamente a representação do campo. Desta forma, Lévi-Strauss deixa claro a que centro urbano o mundo selvagem pesquisado se opõe (ou, de outra forma, ele está mostrando qual centro urbano é possível nos trópicos). Referindo-se à capital paulista, afirma:

Nas cidades do Novo Mundo, quer se trate de Nova York, Chicago ou São Paulo, que com esta foi muitas vezes comparada, não é propriamente a falta de reminiscências que me choca; essa ausência é um elemento da sua significação [...]. Estas cidades são jovens e extraem dessa juventude sua essência e justificação. A passagem dos séculos representa uma promoção para as cidades européias; para as americanas, a simples passagem dos anos é uma degradação. Não foram apenas construídas recentemente, mas de forma tal que podem renovar-se com a mesma velocidade com que foram erguidas, isto é, mal. No instante em que se erguem novos bairros, quase não chegam a ser elementos urbanos: são demasiadamente novos para o serem. $\mathrm{O}$ estilo passa de moda, a ordenação arquitetônica primitiva desaparece com as demolições que são exigidas por uma nova impaciência (LÉVI-STRAUSS, 1993, p. 86). 
É necessário contextualizar o lugar ocupado por Lévi-Strauss no Brasil. Entre os anos de 1935 e 1938, é professor da recém-criada Universidade de São Paulo, fazendo parte, juntamente com intelectuais como Pierre Monbeig, Paul Arbousse-Bastide e Roger Bastide, da missão francesa convidada a inaugurar na década de 1930 as atividades universitárias na cidade. A USP era financiada pela burguesia local e pelo jornal $O$ Estado de São Paulo. Lembremos que havia cinco anos os paulistas tinham sido derrotados por Vargas na Revolução Constitucionalista; e que devido à oposição de $O$ Estado, a polícia do Governo Federal chegaria a invadir as dependências do jornal em 1940, intervindo em suas publicações até o fim do Estado Novo.

Lévi-Strauss organiza sua expedição em 1937. Porém, para realizar qualquer trabalho no interior do Brasil era necessária uma licença do Governo, dada pelo Conselho de Fiscalização das Expedições Artísticas e Científicas, criado em 1933 para "vigiar" o território nacional. O pedido de permissão de Lévi-Strauss causou polêmica, por um lado devido às suspeitas de comunismo que pairavam sobre um professor francês amigo de Lévi-Strauss; e por outro, obviamente, por se tratar de pedido feito por um francês professor da USP, ou seja, contratado pela burguesia paulista. Só a intervenção de um dos membros do Conselho, a diretora do Museu Nacional, Heloisa Alberto Torres, fez a licença ser concedida, no início de 1938. Outro apoio essencial foi o de Mário de Andrade, na época secretário de Cultura do Estado de São Paulo, que assumiu a coordenação e o financiamento da excursão (DOMINGUES et al., 1998).

Este ambiente de "politicagem", a começar pela própria relação entre LéviStrauss e a USP, surpreendeu o antropólogo. Na verdade, trabalhando nesta instituição, ele se sentia também funcionário dos donos do jornal $O$ Estado de São Paulo e de outros paulistas "quatrocentões", patronos da USP. Esta situação provavelmente influenciou sua apreensão:

\begin{abstract}
Assim é que uma sociedade limitada distribuiu os papéis entre os seus membros [...]. Nenhuma preocupação real em aprofundar os conhecimentos encontrava-se na base destas vocações. Se por acaso dois indivíduos, em resultado de erro de manobra ou por pura inveja, ocupavam o mesmo domínio ou domínios próximos, passavam a ter a preocupação exclusiva de se destruírem mutuamente, o que faziam com persistência e ferocidade notáveis. Em contrapartida havia troca de visitas entre feudos vizinhos, tudo isso com muitas mesuras, uma vez que todos estavam interessados quer em defender o seu emprego, quer também em aperfeiçoar esse minuete sociológico, cuja execução parecia trazer um deleite inesgotável à sociedade paulista (LÉVISTRAUSS, 1993, p. 91).
\end{abstract}

Sobre os jovens acadêmicos da USP, a quem orientava pesquisa e estudo em etnologia, Lévi-Strauss comenta, em Tristes trópicos:

Quanto aos nossos estudantes, queriam saber muito; qualquer que fosse o campo do saber, só a teoria mais recente merecia ser considerada. Fartos de festins intelectuais do passado, que de resto só conheciam de ouvido, pois nunca liam as obras originais, mostravam enorme entusiasmo pelos novos pratos. Seria preciso, no que lhes diz respeito, falar de moda e não de cultura: idéias e doutrinas não apresentam aos seus olhos um valor intrínseco, eram apenas considerados por eles como instrumento de prestígio, cuja primazia 
tinham de obter. Partilhar uma teoria conhecida por outros era o mesmo do que usar roupa pela segunda vez; corria-se o risco de um vexame (LÉVI-STRAUSS, 1993, p. 94).

Como fica claro nesta passagem, tais tendências são vistas por Lévi-Strauss como um defeito próprio de uma sociedade nova, sem rigor acadêmico, que, todavia, sente a necessidade de, em primeiro lugar, sobressair-se em relação aos demais membros da sociedade, e também de dialogar com o pensamento mundial.

O ponto de vista exposto pelo antropólogo francês, acerca da constituição social, política e acadêmica da cidade de São Paulo, representa uma voz não-nacional, européia e até imperialista, que acaba por construir uma representação de São Paulo e do Brasil. Incomodamente, o discurso de Lévi-Strauss não diferencia o campo e o espaço urbano, numa postura bem diferente de Antonio Candido, que expôs a existência de uma organização social camponesa própria - relativamente independente até meados do século XX - estabelecida no interior e nas proximidades do Estado de São Paulo (CANDIDO, 1971). O livro de Lévi-Strauss, ao contrário, evidencia os contrastes e sobreposições do contexto urbano, que até hoje não parecem claros para um olhar menos distanciado, como o da própria elite paulista.

Tristes trópicos permite pensar que a caipirice não havia sido expulsa para a periferia da cidade, e permanecia no centro. Entretanto, como Lévi-Strauss também nos mostra, a elite local revelava uma forte crença no crescimento físico como sinal de progresso, sem notar que este não exclui, mas é paralelo, ao provincianismo e ao crescimento da pobreza. Neste sentido, o texto de Lévi-Strauss estabelece uma importante crítica ao Brasil, com sua tendência a homogeneizar a sociedade sob a lógica da cidade moderna, cultural e economicamente desenvolvida - um modelo europeu.

Em 1956, no mesmo ano em que Tristes trópicos era publicado em língua portuguesa, Guimarães Rosa lançava Grande sertão: veredas. Nesta obra Riobaldo, o personagem-narrador, expõe oralmente suas memórias a um homem desconhecido, mas que, se depreende, é de origem urbana.

A oposição entre campo e cidade não se encontra no texto, geográfica nem culturalmente. "Sertão. O senhor sabe: sertão é onde manda quem é forte, com as astúcias. Deus mesmo, quando vier, que venha armado! E bala é um pedacinhozinho de metal..." (ROSA, 2001, p. 35). O sertão, na verdade, representa uma realidade social com dimensões amplas. As questões sobre as quais pensa Riobaldo não são específicas do campo. Elas também se aplicam aos problemas urbanos. Por exemplo, sua opinião sobre a existência ou não de Deus, em certo momento conduz a uma afirmação referente aos interesses individuais presentes em construções coletivas, como o Estado:

Ah, eu sei que não é possível. Não me assente o senhor por beócio. Uma coisa é pôr idéias arranjadas, outra é lidar com país de pessoas, de carne e sangue, de mil-e-tantas misérias... Tanta gente - dá susto se saber - e nenhum se sossega: todos nascendo, crescendo, se casando, querendo colocação, comida, saúde, riqueza, ser importante, querendo chuva e negócios bons... (ROSA, 2001, p. 31). 
Da mesma forma, falando sobre o pensamento dos jagunços, expõe a verdade sobre posturas ditatoriais de toda ordem: "Querer o bem com demais força, de incerto jeito, pode já estar sendo se querendo o mal, por principiar. Esses homens! Todos puxavam o mundo para si, para o concertar consertado. Mas cada um só vê e entende as coisas dum certo modo" (ROSA, 2001, p. 32).

Guimarães Rosa não "utiliza" a literatura como forma, digamos, panfletária de expor uma posição política. O que, por outro lado, não significa que Grande sertão seja uma obra apolítica. Pelo contrário, nela temos talvez o argumento mais contundente contra o discurso estatal que homogeneíza o camponês dentro de um projeto urbano de nação. O sertão de Guimarães não é um oposto da cidade; é ele próprio todo o mundo, como diria Riobaldo.

Entre suas muitas possibilidades de leitura, Grande Sertão pode ser pensado como um texto que trata não apenas do campo, mas do Brasil. Neste sentido, o romance recria no sertão literário as relações sociais de poder, e as tentativas estatais de transformar um contingente humano cultural, social e economicamente diversificado numa república, que supostamente representaria uma forma de vida coletiva harmoniosa.

Referindo-se à proposta roseana de repensar os pressupostos políticos em que se funda o Estado brasileiro, Ettore Finazzi-Agrò afirma, em Um lugar do tamanho do mundo, que

para entender os limites e as distinções típicas do espaço urbano, Rosa nos obriga a acompanhá-lo na travessia de uma dimensão aparentemente ilimitada e indistinta, que só pode ser entendida no abandono da lógica costumeira, no ultrapassamento tanto da razão urbana quanto da des-razão sertaneja, para chegar a uma forma de pensamento nova e antiqüíssima ligando os contrários, confundindo o sujeito que pensa com o objeto que é pensado [...] (FINAZZI-AGRÒ, 2001, p. 112).

Grande sertão opera fora da lógica dicotômica do Estado moderno, lógica pautada na constante seleção e exclusão de elementos simbólicos. À medida que o leitor vai se aproximando do ilogismo roseano, também se afasta da lógica à qual está tão habituado a ponto de não questionar fundamentos problemáticos como, por exemplo, a noção de pátria. Então, torna-se evidente

um Brasil, de fato, suspenso entre a afirmação de uma Pátria e a persistência de mil pátrias, entre universalismo e particularismo, entre cidade e interior, entre progresso e atraso, entre autonomia e dependência, entre primeiro e terceiro mundo, e que o escritor deixa, justamente, boiar nessa indecisão, nesse "entrelugar" (FINAZZIAGRÒ, 2001, p. 102).

Analisadas dentro de um diálogo com o Estado nacional ao qual se referem, Grande sertão e Tristes trópicos funcionam como obras opositoras ao discurso estatal brasileiro que massifica homogeneamente a população urbana na mesma medida em que aparta dela qualquer elemento não-urbano. De uma perspectiva externa, temos Tristes trópicos, obra que expõe de forma exemplar os desajustes entre a Europa, com seu modelo estatal a ser seguido, e o Brasil, esforçando-se para se equiparar a este 
modelo, formando por isso, já de saída, um projeto nacional problemático. De uma perspectiva interna, por sua vez, temos Grande sertão, texto que apresenta um projeto literário de nação que além de não se deixar apreender por discursos nacionalistas fáceis, mostra a existência de um Brasil livre e excluído (livre porém excluído e livre porque excluído da ordem estatal).

Provavelmente um dos fatos que de forma mais clara expõe a representação estatal do campo, pelo menos na primeira metade do século XX, é a apreensão do camponês como símbolo nacional. Pelo menos até a década de 1950, podemos perceber uma relação no mínimo ambígua entre campo e Estado. Por um lado, há uma valorização de imagens não-urbanas, como a do caipira, chegando muitas vezes a representações fantásticas. ${ }^{1}$ Por outro lado, não houve - e ainda não há - uma política governamental que atendesse às necessidades das sociedades rurais. Esta ambigüidade ficou ainda mais evidente quando a política nacional desviou-se da economia cafeeira e passou a priorizar a indústria de base e a formação de uma classe operária urbana controlada pelo Estado. A roupagem moderna da política varguista não mudou a relação entre Estado e o não-urbano, pelo contrário. Entre as muitas medidas desenvolvidas pelo Governo no setor trabalhista, praticamente nada dizia respeito ao trabalhador rural.

Entre as décadas de 1940 e 1970, figurava na Carteira de Trabalho:

A carteira, pelos lançamentos que recebe, configura a história de uma vida. Quem a examinar, logo verá se o portador é um temperamento aquietado ou versátil; se ama a profissão escolhida ou ainda não encontrou a própria vocação; se andou de fábrica em fábrica, como uma abelha, ou permanece no mesmo estabelecimento, subindo a escala profissional. Pode ser um padrão de honra. Pode ser uma advertência (NOGUEIRA in REVISTA HISTÓRIA VIVA, ed. temática, n. 4, p. 34).

O aviso presente na Carteira de Trabalho mostra que, se por um lado o Governo de Vargas representava a conquista e o reconhecimento dos direitos sociais do trabalhador assalariado urbano, por outro deixava claro o desejo de controlar e cooptar a classe operária. Também fica evidente o tratamento dado a quem não se enquadra nos padrões de trabalho, obediência e patriotismo. Enquadrado nestes padrões está o cidadão; entre as principais formas inassimiláveis pelo Estado temos o camponês, que, por não ser sequer urbano, está muito distante do cidadão exemplar.

Entretanto, contraditoriamente temos a massificação cultural articulada pelo próprio Governo de Getúlio Vargas. Além do controle da imprensa, são incentivadas festas populares, entre elas as de temas rurais. A partir da década de 1930, as músicas de temas rurais, principalmente a música caipira, começam a fazer muito sucesso nas rádios. Na sua campanha para a eleição de 1950, Vargas contratou a dupla caipira Vieira e Vieirinha para animar seus comícios. Desta forma ambígua o não-urbano era representado, ora como elemento nacionalista, ora como elemento excluído, com o intuito de tornar evidente o padrão de homem urbano pretendido pelo Estado.

Ter em mente que as categorias "urbano" e "não-urbano" estão estreitamente ligadas à postura nacionalista é muito importante. Em primeiro lugar, porque as atenções do Estado brasileiro durante o segundo quartel do século XX em grande parte 
estavam voltadas para a tensa relação entre as potências mundiais, situação que culminaria na Segunda Guerra Mundial. A industrialização brasileira é prova disso, pois o desenvolvimento da indústria de base visava à auto-suficiência econômica e à conseqüente soberania do país. O próprio interesse efetivo de Vargas pelo interior do Brasil, cuja mostra principal talvez seja a construção da cidade de Goiânia, não foi motivado por uma idéia de desenvolver o interior, converter o espaço não-urbano em urbano, mas pelo receio de uma invasão estrangeira. Desta forma, o nível da representação de imagens não-urbanas indica um problema mais amplo, o da relação opositora entre os Estados modernos. ${ }^{2}$

Se refletirmos a partir de textos que tratam da relação existente entre os Estados modernos, principalmente entre os Estados coloniais e suas ex-colônias, poderemos perceber com maior clareza que as imagens não-urbanas são articuladas dentro da formação cultural do Estado nacionalista brasileiro em sua oposição a outros Estados. Edward W. Said, em Cultura e imperialismo, discute as tensões políticas e culturais que há entre impérios e colônias. Aperfeiçoando conceitos de seu livro anterior, Orientalismo, o autor analisa a maneira como o ocidente engendra, desde antes da onda imperialista do século XIX, imagens do oriente e como elas transmitem sua repercussão do âmbito cultural para o político-econômico.

Todavia, Said mostra que há discursos de oposição por parte das ex-colônias. As estratégias destes discursos são as mais diversas, mas há uma tendência política: a formação de Estados nacionais pós-coloniais, pautados no próprio nacionalismo europeu. A eleição de artefatos nacionais como símbolos de oposição a outros Estados é um procedimento normal destes Estados nacionais. No caso brasileiro, um dos símbolos de nacionalidade diz respeito a formas tradicionais de vida relacionadas ao campo.

Houve, e ainda há, discursos que afirmam existir em imagens não-urbanas, como a do caipira ou do sertanejo nordestino, uma genuinidade brasileira que se perderia no contato com a cidade, considerada um espaço cosmopolita, e daí descaracterizador. A relação não se resume a campo e cidade, uma vez que esta se pauta na idéia de nação o que pressupõe a oposição a tudo que for considerado não-nacional. Assim, o nãourbano, opositor à cidade moderna, transforma-se em elemento de oposição ao nãonacional. E o curioso é que, mesmo sendo símbolo nacional, o não-urbano continua relacionado dicotomicamente com o urbano. Isto é, o não-urbano é símbolo nacionalista, mas não é cidadão politicamente pleno.

Outra forma de se opor à cultura de outros Estados é a equiparação científica e intelectual, o que pressupõe normalmente a criação de espaços acadêmicos. Como exemplo brasileiro deste projeto de independência cultural podemos citar a criação da Universidade de São Paulo. A missão francesa, da qual fez parte Lévi-Strauss, indica a impossibilidade - não apenas em âmbitos intelectuais - de um nacionalismo nãoocidental. A importação de "conhecimento" europeu talvez possa ser vista como "uma reação negativa a uma demonstrada inferioridade cultural e social, uma imitação do comportamento político "ocidental" (SAID, 1995, p. 274).

Os conceitos de Edward Said expostos em Cultura e imperialismo são importantes notadamente para a análise de Tristes trópicos. Em primeiro lugar, porque permite pensar Lévi-Strauss como o europeu que, mesmo tentando ter consciência da limitação de seu ponto de vista, acaba representando o outro. Neste caso, Said nos 
permite ver que a responsabilidade por esta representação não é apenas de Lévi-Strauss, afinal foi o Estado brasileiro, ou pelo menos algum segmento dele, que contratou a missão francesa. E "missões", sabemos, têm sempre caráter civilizatório. Em segundo lugar, porque permite não perder de vista contradições da estratégia nacionalista brasileira de se opor a outros Estados, ou mais especificamente, porque permite analisar como este projeto de soberania cultural lidou com a presença de Lévi-Strauss.

Em Tristes trópicos temos um olhar europeu, de um francês "missionário", que em seu texto sobre o Brasil, vê e é visto. em Grande sertão: veredas temos uma crítica à lógica soberana, a partir da criação de um espaço que não se deixa representar como não-urbano. Como lidar com um texto que, com autoridade missionária, acusa uma corrupção em nossa origem? Talvez com um texto que não se permite racionalizar, teorizar, representar.

Em 1965, numa conversa-entrevista concedida ao crítico alemão Günter Lorenz, Guimarães Rosa definiu a brasilidade como um "sentir-pensar". Este conceito talvez ajude a entendermos o texto de Rosa como uma desestabilização da segurança dos discursos institucionais, a partir da proposição de um outro código, que, para sustentarse, lança mão, não de um sentimento, mas do "sentir". Não deixa de ser sintomática a pergunta desconcertada do crítico: “que diabos é um sentir-pensar?”, principalmente se consideramos que, na mesma ocasião, Rosa afirma enigmaticamente a necessidade de a Europa, num futuro próximo, voltar-se para sua neta bastarda, a América Latina (LORENZ, 1983, pp. 91 e 97).

\footnotetext{
${ }^{1}$ Quanto a opiniões contrárias a esta valorização, como foi a de Monteiro Lobato e de Rui Barbosa, nas duas primeiras décadas do século XX, elas parecem ter desaparecido de todo nas décadas seguintes. Além disso, estas opiniões, pelo menos com base em Lobato e Rui, tinham mais o objetivo de criticar os governantes desinteressados pelos problemas do campo, do que propriamente uma agressão contra o modo de vida das sociedades rurais. Ou seja, o objetivo era alertar justamente para a contradição de um discurso que glorifica a representação e deixa morrer o representado.

2 Paulo Bertran, no ensaio "O Estado Novo marcha para o Oeste", afirma que "em 1937, em Genebra, no plenário da Sociedade das Nações, o embaixador japonês barão Shudo levantou a tese de que as regiões inexploradas de vários países deveriam ser cedidas a nações ricas e populosas, como o Japão, naturalmente". Ainda segundo Bertran, estas pretensões dos paises do eixo mobilizaram estrategistas brasileiros, que "concluíram que a Amazônia se autodefendia do colonizador branco com suas selvas, suas doenças e seu calor", diferentemente da "situação da pré-Amazônia mato-grossense e goiana, com suas extensas faixas de campos e cerrados habitáveis" (BERTRAN in HISTÓRIA VIVA, ed. temática, n. 4, p. 71).
}

\section{REFERÊNCIAS}

AGAMBEN, Giorgio. Homo sacer I: o poder soberano e a vida nua. Belo Horizonte: UFMG, 2002.

BATAILLE, Georges. El estado y el problema del fascismo. Murcia: Universidad de Murcia, 1993. (Colección Hestia-Dike) 
BERTRAN, Paulo. O Estado Novo marcha para o Oeste. Revista História Viva. Série Grandes Temas, n. 4. São Paulo; Rio de Janeiro: Duetto Editorial, s/d.

CANDIDO, Antonio. O homem dos avessos. In: COUTINHO, E. F. (org). Guimarães Rosa. São Paulo: Civilização Brasileira, 1983. (Coleção Fortuna Crítica, n. 6)

Os parceiros do Rio Bonito: estudo sobre o caipira paulista e a transformação dos seus meios de vida. 2. ed. São Paulo: Duas Cidades, 1971.

DOMINGUES, Heloisa M. B.; MONTE-MÓR, Patrícia; SORÁ, Gustavo. Retrato brasileiro dos "Tristes trópicos". Ciência Hoje, v. 24, n. 144. Rio de Janeiro: Instituto Ciência Hoje, nov. 1998.

FINAZZI-AGRÒ, Ettore. Um lugar do tamanho do mundo: tempos e espaços da fícção em João Guimarães Rosa. Belo Horizonte: UFMG, 2001.

LEACH, Edmund. As idéias de Lévi-Strauss. São Paulo: Cultrix, 1995.

LÉVI-STRAUSS, Claude. Tristes trópicos. Lisboa: Edições 70, 1993.

LORENZ, Günter. Diálogo com Guimarães Rosa. In: COUTINHO, E. F. (org). Guimarães Rosa. São Paulo: Civilização Brasileira, 1983. (Coleção Fortuna Crítica, n. 6)

NOGUEIRA, Arnaldo José França Mazzei. O trabalho sob a tutela do Estado. Revista História Viva. Série Grandes Temas, n. 4. São Paulo; Rio de Janeiro: Duetto Editorial, s/d.

ROSA, João Guimarães. Grande sertão: veredas. 19 ed. Rio de Janeiro: Nova Fronteira, 2001.

SAID, Edward W. Cultura e imperialismo. São Paulo: Companhia das Letras, 1995.

WILLIAMS, Raymond. O campo e a cidade. São Paulo: Companhia das Letras, 2000. 